\title{
Coronavirus syndrome: COVID-19 psychotrauma
}

\author{
Nadezhda V Soloveva (1), Ekaterina V Makarova (2), Irina V. Kichuk (3)
}

(1) Joint-stock company "Scientific Center of Personalized Medicine", Moscow, Russia; (2) Somatic rehabilitation, reproductive health and active aging department of Federal Atate Budgetary Institution "National Medical Research Center of Rehabilitation and Balneology" of the Ministry of Health of Russian Federation, Moscow, Russia; (3) Department of Neurology, Neurosurgery and Medical Genetics of the Medical Faculty of the N.I. Pirogov Russian National Research Medical University, Moscow, Russia

This article is distributed under the terms of the Creative Commons Attribution Noncommercial License (CC BY-NC 4.0) which permits any noncommercial use, distribution, and reproduction in any medium, provided the original author(s) and source are credited.

\begin{abstract}
The authors propose term "coronavirus syndrome" for the mental disorder that is a psychical response to the global problem of COVID-19 pandemic. This syndrome will affect up to $10 \%$ of the population and we could already observe acute stress reactions to the spread of the infection and changes in people's ordinary lifestyle. However, the most severe response will be seen later, in this case the catastrophe is similar to the clinical picture of post-traumatic stress disorder. The problem is that coronavirus syndrome will affect the working capacity of population at the period, when economical recovery is essential. The risk groups are health caregivers who worked in COVID departments; patients recovered from a severe form of the disease; people who have lost their loved ones; and those who have suffered significant financial losses or lost their jobs. Adequate prophylaxis of coronavirus syndrome especially in high-risk groups are important for maintaining global mental health and economy.
\end{abstract}

Key Words: COVID-19, post-traumatic stress disorder, social stress disorder, mental health, prophylaxis, perspectives

Eur J Transl Myol 2020; 30 (4): 9302. doi: 10.4081/ejtm.9302

Coronavirus infection is a novel global disaster, that caught the world community completely unprepared. We may say since the end of the World War II no events of such a powerful and piercing resonance occurred.

The new viral infection has a number of significant features, such as ubiquity, high contagiousness, high mortality rate, significant social and economic consequences that disrupt people ordinary lifestyle, brining dramatic and rapid changes in the normative rules of behavior., ${ }^{1,2}$ We call COVID-19 problem "pandemic", which implies the involvement of everyone on the planet. The meaning of the word " $\pi \tilde{\alpha} \nu$ " (Greek for "all", "across the board") highlights the global nature of the phenomenon. In his recent interview, the psychoanalyst Murray Stein called the COVID-19 problem a "World Shadow". ${ }^{3}$ There is probably not a single person on our planet who has not been touched by the coronavirus now or will not be touched by it in future. This is a critical historical period, which most probably will affect global mental health, perhaps to a greater extent than somatic health, as there is no way to protect ourselves from the flow of information and from the life changes. The actual impact and scale of the problem will be fully understood only after the catastrophe is over. Mental disturbances caused by the coronavirus will have large variations in time and space. Most people will experience acute stress disorder, some will experience post-traumatic stress disorder (PTSD), a number of people will face such outcomes as depressive episodes, neurotic disorders and personality deformities. Thus, the group of mental disorders caused by the COVID-19 pandemic may be identified as "coronavirus syndrome". Our scientific aim was to design a short narrative review about PTSD clinical features and apply this information to the COVID-19 context to highlight the problem of psychological outcomes of the SARS-COV 2 pandemic, to state the higher risk groups and to propose prophylactic measures.

\section{History}

The literature equivalent for PTSD is the "Lost Generation” described by Ernest Hemingway, Francis Scott Fitzgerald, Erich Maria Remarque and other writers of 20th century. The term refers to the generation of people who reached their eighteenth birthday before or 
during World War I. After the end of hostilities such people often could not adapt to peaceful life: they drank, committed suicide or clearly showed PTSD symptoms. ${ }^{4}$ This phenomenon drew the attention of doctors in the 80's of the 20th century. The concept of PTSD had been developed in the USA, and the term "Vietnam syndrome" was introduced to describe mental symptoms and personality changes observed in veterans of the Vietnamese war. ${ }^{5}$ In medical practice of Russian psychiatrists, similar clinical picture was observed in the participants of the Afghanistan and Chechnya wars, and are known as "Afghan" and "Chechen" syndromes. ${ }^{6-8}$ Participation in the battles is not the only cause of psychological trauma that leads to development of a stress disorder. We know numerous descriptions of psychological consequences of catastrophes, ${ }^{9}$ natural disasters (i.e., earthquakes and hurricanes), ${ }^{10,11}$ and terrorism attacks in U.S.A (e.g, September 11, 2001). ${ }^{12}$ Russian publications include the concept of Social Stress Disorder (SSD) to describe how changes in the political system and government affects mental health of the population. In Y.A Aleksandrovskiy's opinion, 13 while PTSD develops in people who have survived dangerous and traumatic situations, SSD is typical of people who have fallen under the influence of macrosocial groupwide psychogenic factors. Economic and social phenomena affecting a large number of people could also lead to significant mental changes and SSD, we could mention "Great Depression" phenomenon as an example, which developed in the 30's of the 20th century in the U.S.A. during economic crisis. The phenomenology of SSD does not essentially differ from the disorders observed in people who have gone through extreme conditions, but it is caused by common reasons and develops simultaneously in a large number of people.

\section{Clinical signs of the stress disorders}

The clinical picture of PTSD usually develops from 30 days to 6 months after the onset of a traumatic episode and affects up to $10 \%$ of the trauma-exposed individuals. ${ }^{14}$ Table 1 . shows that his disease is manifested in psychological disadaptation (mental dysfunction) and accompanied by the variety of intraand interpersonal conflicts, loss of meaning in life or its reinterpretation, collapse of the former ideals and loss of faith in a successful future, in other words, it is a kind of existential crisis. ${ }^{15}$ The heavier the trauma, the more likely the disorder is to develop, however, it does not occur in all people, no matter how serious the trauma is. Thus, there are a number of factors that determine a person's vulnerability and ability to recover quickly. Frueh et al. in their work found that PTSD after wars occurred in many people who had never taken part in battles. $^{22}$ The risk of PTSD development in a person depends on several exogenous factors (type of job, lockdown environment, losses) and endogenous factors (comorbid mental disorders, psychological and biochemical features). Studies aimed for assessing
Table 1. Clinical signs of stress disorders

The clinical traits include: ${ }^{16-21}$

a) Recurrent memories of stressful events

b) Emphasis of personality traits

c) Reduced social activity, distrust in other people

d) Thought disorder, development of pathological ideas and attitudes

e) Development of obsessions and compulsions

f) Affective symptoms associated with high emotional excitement, aggression, irritability or oppression, apathy and depression

g) Refusal to accept reality

h) Alcoholism, drug abuse, deviant behavior

i) Difficulties in concentration, cognitive deficit

j) Sleep disturbances in the form of poor sleep quality, difficulty falling asleep, nightmares or hypersomnia.

morphological and biochemical substance of PTSD have revealed reductions in hippocampal volume (however, this phenomenon may be a prerequisite to the development of maladaptation in response to the trauma $^{23}$ and specific neurotransmitter changes (dysfunctions in monoaminergic systems, ${ }^{24}$ gaminobutyric acid receptor dysfunctions ${ }^{25-26}$ and reduction of cortisol concentration in blood plasma due to induction of negative feedback on hypothalamicpituitary-adrenal axis. ${ }^{27}$ As a matter of fact, mental and/or somatic responses to stressful events are absolutely natural. Not every manifestation of such responses should be regarded as pathological; moreover, a certain level of stress will enhance future adaptive abilities of the body. ${ }^{28}$ According to psychologist's opinion emotions expression, re-experiencing and talking about one's fears, anger and irritation, followed by the analysis of the negative experience, promote integration of the trauma and lead to a faster compensation of one's mental condition. ${ }^{29,30} \mathrm{~A}$ stress disorder that lasts more than three months is considered to be chronic, ${ }^{31}$ however, normal parameters in this matter are always patient-specific, and the doctor should pay attention to the signs of disadaptation, degree of decline in cognitive function, working capacity and quality of life, as well as the critical thinking presence. In addition, there are biochemical stress-vulnerability factors associated with PTSD. One of the biological factors is the genetic profile of an individual, which is related to his or her mental flexibility. The polymorphism of the gene encoding the enzyme catechol-o-methyltransferase (COMT) can be mentioned among the most studied ones. Its function is to degrade the adrenal hormones produced during stress. The rate of mental reactions and mental adaptivity in humans depends on the rate of the degradation of these 
hormones. The variant of the genotype G/G (rs4680 Val158Val) with a high rate of stress hormones degradation allows performances as mobilizing, making quick decisions, ignoring external stimuli under stressful conditions. ${ }^{32}$ The risk of coronavirus syndrome is low in such individuals. The variant of genotype G/A (rs4680Val158Met) with a lower rate of stress hormones degradation products does not allow mental health to recover as quickly, lingering on stressful situations occurs; such people may be exposed to coronavirus syndrome in combination with other risk factors. The variant of genotype A/A (rs4680Met158Met) with low rate of utilization of stress hormones is associated with high risk of development of anxiety disorders, development of dependent behavior; coronavirus syndrome possibility in such patients is high. ${ }^{33}$ Another biological factor is the history of hazards, which make the patient's mind less flexible to changes. These hazards include hypertension, diabetes, obesity, atherosclerosis of brain vessels, thyroid disease, imbalance of sex hormones, history of craniocerebral injuries, comatose

Table 2. Groups of people at higher or lower risk of developing PTSD

Group at higer risk of PTSD development

a) Medical workers and especially doctors who help patients with COVID-19 under the conditions of overload, lack of information about the disease, lack of vaccines and specific medicines, lack of medical and personal protective equipment

b) People of other jobs, who continued working during the pandemia, putting themselves at great risk of being infected

c) COVID-19 patients, especially those who needed hospitalization

d) People who have lost their relatives and loved ones

e) People who have lost their jobs, business and suffered financial losses

f) Tourists being locked down in foreign countries;

g) Psychoactive substance abusers

h) Those who suffer mental diseases and disorders

i) Susceptible to stress individuals and those who have weak coping strategies

Group at lower risk of PTSD development

a) People, experiencing no additional traumatic events during pandemia

b) Individuals, who had not fallen ill or experienced asymptomatic disease

c) Mentally sound people with good coping strategies and adaptation abilities

d) People living in a safe and favorable environment, which provides less stressful triggers during lockdown

e) People with a high income states, neuroinfections, intoxications (with alcohol, drugs, carbon monoxide, various toxic chemicals), shortage of nutrients, vitamins, micro and macro elements of various genesis, etc. ${ }^{34}$ Among personal and psychological features, the following factors increase the risk of PTSD development: childhood traumas, history of psychiatric diseases in the patient and his or her family, low level of education, lack of support from relatives, high base level of stress, propensity for avoidant behavior and passive response to stress. ${ }^{35,36}$

Coronavirus syndrome as a special case of social stress disorder

Coronavirus syndrome is a mental disorder, which represents the body's reaction to the COVID-19 pandemic. We can now only hypothesize how the situation will develop, since it will certainly take time (at least six months from the beginning of the catastrophe) for coronavirus syndrome to be more clearly defined. More than nine months have passed since the first cases of COVID-19 infection in Wuhan were registered, and now we see "the second wave", even more extensive, than the first. Currently people still experience stages of acute stress reactions.

It is important to pay attention to prevention of the development of coronavirus syndrome, because at the moment the society will be fully aware of what has happened and global mental health is particularly vulnerable, it will be critical to preserve the working capacity of the population in order to restore the economy, if possible, and let people maintain their own resources as well. Forewarned is forearmed.

\section{Epidemiology}

Coronavirus syndrome is expected to affect up to $10 \%$ of the world's population touched by the pandemic, similar to PTSD frequency. ${ }^{37}$ This tenth of the population includes people exposed to a combination of psychosocial and biological stress-vulnerability factors. Table 2. shows that in the context of stress disorders all people who contacted COVID-19 catastrophe may be divided in two groups: Group One is the people with high risk of PTSD development, while those of Group Two are people with low risk of PTSD development, that is those who have some protective factors.

\section{Anticipated symptoms of coronavirus syndrome}

In the case of coronavirus syndrome, the clinical picture is likely to be similar to the one of SSD, like the one observed in Russia during "Perestroika". The cause of mental disorders in this case is not a specific traumatic event localized in time, but long-term stressful experience beyond ordinary one, changes in social bonds and life plans, instability and uncertainty of the future, and a large amount of non-constructive disturbing information in mass media. The picture of mental manifestations of coronavirus syndrome can be divided into several stages, by analogy with reactions to other types of stressful events. ${ }^{15-17,31,37}$ 


\section{Stage 1. Acute reaction to stress.}

This reaction lasts for the whole period of the existence of the threat. It can already be observed now and will decline when the epidemiological situation improves and the quarantine measures are lifted. Acute reaction manifests itself by the spectrum from panic and exaggeration of the problem to its denial (some people buy up buckwheat and toilet paper, others go to barbecues). There are several variants of the body's response to stress. In the current situation one type of person reacts with a mental block, narrowed consciousness, sluggishness in mind, negative predictions. The other type demonstrates talkative, excited, energetic and overactive but non-productive behavior. One can clearly see the coronavirus unity in social networks, the abundance of humorous and funny content, at the same time many people experience anxiety, associated with fear of infection and fear of death. In some cases, when people's critical thinking reducing, we see mystic and "conspiracy theories" interpretation of the events. All of these are forms of psychological defense in the face of the disaster. Many people note a distorted time perception (one day seems to last forever) and sleep disorders (difficulties in falling asleep, interrupted sleep, nightmares), decreased motivation and a sense of lostness. In people with a history of mental diseases, exacerbations are likely to occur. In the absence of life routine, the percentage of alcohol and drug consumption gets higher, increasing cases of conflicts and fights. Autonomous and psychosomatic manifestations (such as stress ulcers) are not rare. ${ }^{31}$ In a significant number of people this stage will lead to the mobilization of inner forces, accompanied by specific biological changes in their body, without any clinical manifestations. First of all, gamma aminobutyric acid (GABA) receptors become less sensitive to GABA affinity mediator due to the excessive load. ${ }^{25}$ Then the functioning of the whole monoaminergic system changes, which subsequently leads to dysfunction of serotonin, dopamine, noradrenaline, ${ }^{24,38,39}$ and cortisol concentration in blood plasma decreases (due to the induction of negative feedback on hypothalamicpituitary-adrenal axis). ${ }^{27}$

\section{Stage 2. Transition stage.}

This stage will start only after the real threat disappears and will depend on the degree of change in the dynamic stereotype of life, patient's lifestyle and the extent of biological changes occurred during the first stage. Some people will experience it subacutely, with inner emotional tension, changes in eating habits and sleep disorders. Others may develop depression or anxiety disorder.

\section{Stage 3. Post-traumatic stress disorder}

This stage will develop after the society and individuals are going to recognize the reality of the problem. It is a delayed reaction to stress that will develop up to 6 months
Table 3. Peculiar clinical traits of Stage 3. Posttraumatic stress disorder

a) Personal and social disorientation, a sense of loss of meaning

b) Irritability, emotional lability

c) Sharpening of personality traits

d) Depression, apathy, low muscle tone, decreased efficiency

e) Manic manifestations with low productivity

f) Increased psycho-emotional tension, excessive vigilance, especially to everything that seems threatening to health, personal space, financial well-being; aggravated sense of self, up to egocentrism

after the end of the pandemic. It is important to stress that PTSD may develop in people, who had showed no mental disorders during the first two stages. Table 3 . lists the peculiar clinical traits. At this stage, the most frequent complaints will be: attention disorders, difficulties in remembering and keeping this or that information in mind, and difficulties in reproducing it. This is not directly related to memory disorders, but rather to the fact that patients' attention will be fixed on their past experiences, they will not devote enough attention to everyday life and will be unable to switch over. This will have a negative impact on their working capacity and everyday activities. Their suggestibility will increase, enhancing risks of falling victim to fraud. Everything reminding of the infection or isolation, or the strict discipline measures, will preserve tension. Clinical manifestations may be more serious in doctors working with COVID-19, people who have lost family members and friends, their place of work or business. This group is much more likely to perceive the situation as a personal trauma and, therefore, is at a greater risk of developing a full-scale clinical picture of PTSD with such serious symptoms as: a) Haunting and depressing memories of the traumatic events, re-experiencing the highlights of the epidemic over and over again, sometimes flashbacks (sudden, vivid, recurrent experiences) of business collapse, family breakdown, loss of a loved one, etc. It can be difficult to distinguish flashbacks from reality, patients may show mental aberrations, sometimes demonstrating aggression; b) Re-experiencing of loss, feeling weak and powerless; c) Distressing dreams, difficulty in falling asleep with an influx of unpleasant memories, night awakenings and early awakenings in a state of anxiety; d) Fear that the traumatic event will happen again, phobic/panic attacks; e) Significant decrease in working capacity and apathy, or the development of hyper-asthenia, to the extent of destructive unreasonableness; f) Personality changes.

At this stage low mood is observed, there is no interest in any new or previously important activities, the view of the future is pessimistic; it is difficult for the patient to see the prospects of development, which causes 
irritability and outbreaks of anger; patients tend to search for the guilty side or try to determine the degree of their own guilt, up to starting self-blaming. Somatic abnormalities are frequent. There is a high risk of alcohol and cannabinoids abuse and the use of other psychoactive substances. Biological changes with increased pathological brain activity at this stage can be seen on the electroencephalogram in the form of increased power spectrum and decreased coherence between temporal, temporoparietal and parietofrontal brain regions (T.W. Lee et al. 2011) ${ }^{40}$ and in the form of overall tendency to desynchronization: increased power of beta rhythm, decreased relative representativity of alpha range. ${ }^{41-43}$ Possible complications and personality changes that coronavirus syndrome can lead to will be associated with a change in a patient's worldview and understanding of his or her place in the world. The complications are dangerous not only by reducing quality of life and social functioning of a person, they can also cause persistent disability and provoke the conversion of the neurotic disorder into an organic one. The complications are associated with the prolongation of the stress response, personality neurotization and psychopathization, as well as the conversion of the neurotic disorder into an organic one (especially when using psychoactive substances). Patients do not only risk losing flexibility of communicative abilities and the ability to adapt to what is happening to them, not only facing sharpening of their personality traits (developing explosive, hysterical, demonstrative or schizoid traits) but also becoming cynical, prone to antisocial behavior or inertia, limiting their communication to "fellow sufferers" only, often against the background of alcohol and/or drug abuse. There is also the risk of suicide.

\section{Prevention and treatment}

All specialists note that PTSD treatment is a complicated and time-consuming task. The National Institute for Health and Care Excellence (NICE) offers the following principles in its standards of care for patients with stress disorders $(2018)^{17}$ : a) Support (provided by health care professionals, specific support groups), providing all relevant information; b) creating safe environment; c) involving family and friends in the problem; d) actively interacting with the patient during the process of treatment planning; e) actively monitoring the patient's condition. It is very important to start therapy in patients with acute stress disorder on time to prevent the development of a chronic PTSD. Studies show that treatment is much more successful in the acute period. ${ }^{31,37}$ However, not everyone realizes having any problems or considers it necessary to see a psychiatrist or psychotherapist during this period. In the cases of lowrisk patients health caregivers could recommend:

\section{General prophylactic measures and healthy lifestyle}

a) normalisation of sleep-wake schedule; b) moderate physical activity; c) enough dietary intake of vitamins and microelements; d) chronic diseases treatment and compensation. This is important for maintaining good physical condition, that improves body adaptive potential and immune system functionality.

\section{Pharmacological support}

Anxiolytics and moderate sedative drugs may be used to provide metabolic support and improve adaptive potential.

\section{Preventive measures for high-risk patients. \\ Psychotherapy}

Cognitive behavioral therapy with narrative and exposure techniques can be considered as the most effective one. Therapy should be aimed at helping to accept COVID-19 and its consequences as an inevitable reality, at desensitization and reprocessing of the psychological trauma, developing future perspectives and new patterns of behavior. Pharmacological therapy is aimed at relieving anxiety, restoring sleep, treating depression and other mental disorders;

\section{Pharmacotherapy}

It may be used to relieve acute symptoms (antidepressants, antipsychotics, sedatives and anxiolytics).

\section{If PTSD develops}

In case PTSD develops, treatment approaches remain similar, however, the work with a psychotherapist may take much longer and requires prescription of stronger medicinal drugs. ${ }^{44}$ The purpose of treatment is to help the patient's mind to adapt, to help restore social activity, efficiency, improve mental and physical quality of life. Treatment can take from 6 to 12 weeks or more. For some people it takes even much longer. ${ }^{16-18}$

\section{Conclusive remarks}

"Coronavirus syndrome" is a mental disorder that is a psychical response to the global problem of COVID-19 pandemic. This syndrome will affect up to $10 \%$ of the population. We could already observe acute stress reactions to the spread of the infection and changes in people's ordinary lifestyle. However, the most severe response will be seen later, in this case the catastrophe is similar to the clinical picture of post-traumatic stress disorder. The problem is that coronavirus syndrome will affect the working capacity of population at the period, when economical recovery is essential. The risk groups are health caregivers who worked in COVID departments, patients recovered from a severe form of the disease, people who have lost their loved ones and those who have suffered significant financial losses or lost their jobs.

In conclusion, adequate prophylaxis of coronavirus syndrome, especially in high-risk groups, is of paramount importance for maintaining the health of doctors and nurses, global mental health and the world economy. 


\section{List of acronyms}

COMT - catechol-o-methyltransferase

GABA - gamma aminobutyric acid

PTSD - post traumatic stress syndrome

SSD - social stress disorder

\section{Authors contributions}

$\mathrm{NV}$, idea and concept of the review, informational support; EM, bibliographical search, writing the text of the article; IV, scientific consultant.

\section{Acknowledgments}

The Authors thank colleagues of the Department of Neurosciences, University of Padova, Italy and of the A\&C M-C Foundation for Translational Myology, Padova, Italy for discussion and critical readings.

\section{Funding None}

\section{Conflict of Interest}

The authors declare they have no financial, personal, or other conflicts of interest.

\section{Ethical Publication Statement}

We confirm that we have read the Journal's position on issues involved in ethical publication and affirm that this report is consistent with those guidelines.

\section{Corresponding Author}

Ekaterina Makarova, FSBI 'National Medical Research Centre of Rehabilitation and Balneology' of the Ministry of Health of Russian Federation, Novyi Arbat, 32. 121099 Moscow, Russia, Phone: +7(915) 111-41-37. ORCID iD: 0000-0003-3767-8475

Email: baudolinoo@gmail.com

\section{Emails and ORCID iD of Coauthors}

Nadezhda V Soloveva: drsnv@yandex.ru ORCID iD: 0000-0003-2965-9127

Irina V. Kichuk: mail2irina@mail.ru

ORCID iD: 0000-0001-8832-8470

\section{References}

1. Coronavirus disease 2019 (COVID-19) Situation Report \#88. World Health Organization (17 April 2020).

2. COVID-19 STRATEGY UPDATE. World Health Organization (14 April 2020).

3. An Interview with Murray Stein, Ph.D by Rev. Dr. Robert S Henderson. A World Shadow: COVID-19. Chiron publications. 2020 March. Available at: https://chironpublications.com/a-world-shadowcovid-19

4. Madsen, Alex. Sonia Delaunay: Artist of the Lost Generation. 2015. Open Road Distribution. ISBN 9781504008518.

5. Bremner JD, Southwick SM, Darnell A, Charney DS. Chronic PTSD in Vietnam combat veterans: course of illness and substance abuse. Am J Psychiatry 1996;153:369-75

6. Soldatkin VA, Snedkov EV, Sukiasyan SG. Vietnamese, Afghan, Chechen, Donbass syndrome. Evolution of views on the nature of post-traumatic stress. In the book: XVI Congress of Psychiatrists of Russia. All-Russian scientific-practical conference with international participation "Psychiatry at the stages of reform: problems and prospects" Abstract. Moscow, 2015: 495 (in Russ.).

7. Sharova N.A. Comparative analysis of the Vietnamese and Afghan syndromes. NaukaRastudent.ru. 2014;12-2(12):6 (in Russ.)

8. Leukhova MG, Manukyan GI, Hopiyaynen OA. Aggression: Chechen syndrome. In Sat: Social Aggression. Third Kuzbass philosophical readings. Materials Int. conf. in 2 parts. 2004: 95-98 (in Russ.).

9. Sandifer PA, Walker AH. Enhancing Disaster Resilience by Reducing Stress-Associated Health Impacts. Front Public Health 2018; 6:373. doi: 10.3389/fpubh.2018.00373

10. Shinfuku N. Disaster mental health: lessons learned from the Hanshin Awaji earthquake. World Psychiatry 2002;1(3):158-9.

11. Pietrzak RH, Southwick SM, Tracy M, et al. Posttraumatic stress disorder, depression, and perceived needs for psychological care in older persons affected by Hurricane Ike. J Affect Disord 2012;138:96-103. doi: 10.1016/j.jad.2011.12.018

12. Neria Y, DiGrande L, Adams BG. Posttraumatic stress disorder following the September 11, 2001, terrorist attacks: a review of the literature among highly exposed populations. Am Psychol 2011;66:429-46. doi: 10.1037/a0024791

13. Alexandrovsky YuA Social stress disorders. RMJ 1996;3:117-126 (in Russ.).

14. Stein DJ, Seedat S, Iversen A, Wessely S. Posttraumatic stress disorder: medicine and politics. The Lancet 2007;369(9556):139-44. doi: 10.1016/S01 40-6736(07)60075-0

15. Kuester A, Köhler K, Ehring T, et al. Comparison of DSM-5 and proposed ICD-11 criteria for PTSD with DSM-IV and ICD-10: changes in PTSD prevalence in military personnel. Eur J Psychotraumatol 2017;8:1386988. doi: 10.1080/ 20008198.2017.1386988

16. American Psychological Association. Clinical practice guideline for the treatment of PTSD in Adults. (2017). Retrieved from http://www. apa.org/about/offices/directorates/guidelines/ptsd.p df.

17. National Collaborating Centre for Mental Health (UK). Post-traumatic stress disorder. (NICE Clinical Guidelines, No. 116) Published date: 05 December 2018. ISBN: 978-1-4731-3182-8 Available from: https://www.nice.org.uk/guidance/ 
ng116/resources/posttraumatic-stress-disorder-pdf66141601777861

18. Canadian Agency for Drugs and Technologies in Health. Treatment for Post-Traumatic Stress Disorder, Operational Stress Injury, or Critical Incident Stress: A Review of Guidelines [Internet]. CADTH Rapid Response Reports.; 2015 Apr. CADTH Rapid Response Reports. Available from: https://www.ncbi.nlm.nih.gov/books/NBK304757/ pdf/Bookshelf_NBK304757.pdf

19. Fastovtsov GA, Sokolova EA. PTSD and comorbid mental disorders. Russian Psychiatric Journal 2012;3:77-82 (in Russ.).

20. Tushkova KV, Bundalo NL. Features of the manifestations of post-traumatic stress disorder of varying severity in men and women. Siberian Medical Review 2011;68:80-4 (in Russ.).

21. Gilpin NW, Weiner JL. Neurobiology of comorbid post-traumatic stress disorder and alcohol-use disorder. Genes Brain Behav 2017;16:15-43. doi: 10.1111/gbb.12349.

22. Frueh B, Elhia J, Grubaugh A, et al. Documented combat exposure of veterans seeking treatment for combat related posttraumatic stress disorder: review of records from the US National Personnel Records Center. Br J Psychiatry 2005;186: 467-72.

23. Kitayama N, Vaccarino V, Kutner $M$, et al. Magnetic resonance imaging (MRI) measurement of hippocampal volume in posttraumatic stress disorder a meta-analysis. J Affect Disord 2005;88:79-86.

24. Connor KM, Davidson JRT. The role of serotonin in posttraumatic stress disorder neurobiology and pharmacotherapy. CNS Spectrums 1998;3S2:4351.

25. Bremner JD, Innis RB, Southwick SM, et al. Decreased benzodiazepine receptor binding in prefrontal cortex in combat-related posttraumatic stress disorder. Am J Psychiatry 2000;157:1120-6.

26. Harvey BH, Oosthuizen F, Brand L, et al. Stressrestress evokes sustained iNOS activity and altered GABA levels and NMDA receptors in rat hippocampus. Psychopharmacology 2004;175:494502.

27. Yehuda R. Current status of Cortisol findings in post-traumatic stress disorder. Psychiatr Clin North Am 2002;25:341-68.

28. Charney D. Psychobiological mechanisms of resilience and vulnerability: Implications for successful adaptation to extreme stress. Am J Psychiatry 2004;161:195-216. doi: 10.1176/appi. ajp.161.2.195.

29. Brady F, Warnock-Parkes E, Barker C, Ehlers A. Early in-session predictors of response to traumafocused cognitive therapy for posttraumatic stress disorder. Behav Res Ther 2015;75:40-7. doi: 10.1016/j.brat.2015.10.001
30. Mathew AR, Cook JW, Japuntich SJ, Leventhal AM. Post-traumatic stress disorder symptoms, underlying affective vulnerabilities, and smoking for affect regulation. Am J Addict 2015;24:39-46. doi: 10.1111/ajad.12170

31. Kessler RC, Sonnega A, Bromet E, et al. Posttraumatic stress disorder in the National Comorbidity Survey. Arch Gen Psychiatry 1995;52:1048-60.

32. Danzi BA, La Greca AM. Genetic pathways to posttraumatic stress disorder and depression in children: Investigation of catechol-Omethyltransferase (COMT) Val158Met using different PTSD diagnostic models. J Psychiatr Res 2018;102:81-86. doi: 10.1016/j.jpsychires.2018. 03.014

33. Winkler EA, Yue JK, Ferguson AR, et al. TRACKTBI Investigators. COMT Val158Met polymorphism is associated with post-traumatic stress disorder and functional outcome following mild traumatic brain injury. J Clin Neurosci 2017;35:109-16. doi: 10.1016/j.jocn.2016.09.017

34. Malejko K, Abler B, Plener PL, Straub J. Neural Correlates of Psychotherapeutic Treatment of Posttraumatic Stress Disorder: A Systematic Literature Review. Front Psychiatry 2017;8:85. doi: 10.3389/ fpsyt.2017.00085

35. Brewin CR, Andrews B, Valentine JD. Metaanalysis of risk factors for posttraumatic stress disorder in trauma-exposed adults. J Consult Clin Psychol 2000;68:748-66.

36. DiGangi JA, Gomez D, Mendoza L, et al. Pretrauma risk factors for posttraumatic stress disorder: A systematic review of the literature. Clinical Psychology Review 2013;33:728-44.

37. Bisson JI, Roberts NP, Andrew M, et al. Psychological therapies for chronic post-traumatic stress disorder (PTSD) in adults. Cochrane Database Syst Rev 2013;(12):CD003388. doi: 10.1002/14651858.CD003388.pub4

38. Snyder K. Stress, Monoamines, and Cognitive Flexibility. Publicly Accessible Penn Dissertations. 2013, 928 p. http://repository.upenn.edu/ edissertations/928

39. Gesto M, López-Patiño MA, Hernández J, et al. The response of brain serotonergic and dopaminergic systems to an acute stressor in rainbow trout: a time course study. J Exp Biol 2013;216:4435-42; doi: 10.1242/jeb.091751

40. Lee TW, Yu YW, Chen MC, Chen TJ. Cortical mechanisms of the symptomatology in major depressive disorder: A resting EEG study. J Affect Disord 2011;131:243-50. doi: 10.1016/j.jad.2010. 12.015

41. Atlantis E, Fahey P, Cochrane B, Smith S. Bidirectional associations between clinically relevant depression or anxiety and chronic obstructive pulmonary disease (COPD): a 


\section{Coronavirus syndrome: COVID-19 psychotrauma}

Eur J Transl Myol 2020; 30 (4): 9302. doi: 10.4081/ejtm.2020.9302

systematic review and meta-analysis. Chest 2013; 144:766-77. doi: 10.1378/chest.12-1911.

42. Manna CB, Tenke CE, Gates NA, et al. EEG Hemispheric Asymmetries during Cognitive Tasks in Depressed Patients with High versus Low Trait Anxiety. Clin EEG Neurosci 2010;41:196-202. doi:10.1177/155005941004100406,

43. Mathersul D, Williams LM, Hopkinson PJ, Kemp AH. Investigating models of affect: relationships among EEG alpha asymmetry, depression and anxiety. J Biol Psychol 2008;80:560-72. doi: 10.1037/a0012811.

44. Markowitz S, Fanselow M. Exposure Therapy for Post-Traumatic Stress Disorder: Factors of Limited Success and Possible Alternative Treatment. Brain Sci 2020;10:167. doi: 10.3390/brainsci10030167.

Submitted: August 7, 2020

Revision received: November 11, 2020 Accepted for pubblication: November 12, 2020 